\title{
KAJIAN HIDROLOGI DAN SISTEM PENANGGULANGAN AIR HUJAN PADA PENAMBANGAN BIJIH NIKEL (STUDI KASUS PT. BHAKTI PERTIWI NUSANTARA DI SITE SEPO KECAMATAN WEDA UTARA KABUPATEN HALMAHERA TENGAH PROVINSI MALUKU UTARA)
}

\author{
Razak Karim ${ }^{1)}$, Masagus Ahmad Azizi ${ }^{2)}$, Ruslan M Umar ${ }^{1)}$, Nurany $^{4)}$ \\ ${ }^{1)}$ Prodi Teknik Pertambangan Univesitas Muhammadiyah Maluku Utara, Ternate \\ ${ }^{2)}$ Prodi Teknik Pertambangan FTKE Univesitas Trisakti, Jakarta \\ ${ }^{4)}$ Prodi Teknik Pertambangan Universitas Khairun, Ternate
}

\begin{abstract}
ABSTRAK
Hidrologi dilakukan penyelidikan dengan cara pengumpulan data untuk dianalisis terhadap data sekunder meteorologi (curah hujan, hari hujan, suhu udara, kelembaban, tata guna lahan, dan lain-lain) dari lokasi penyelidikan Pit 1 dan Pit 2 PT.Bhakti Pertiwi Nusantara. Dengan data Hidrologi merupakan informasi yang palin penting bagi dalam pengelolaan sistem penanggulangan air hujan, dikarenakan jumlah hujan dan hari hujan sangat berpengaruh terhadap sistem penambangan. Penelitian ini bertujuan untuk mengetahui data hidrologi guna dalam sistem penanggulangan air hujan untuk pemanfaatan pada perancangan tambang terbuka khususnya di kemantapan lereng tambang. Penelitian ini dilakukan dengan cara pengumpalan data sekunder seperti data sebelumnya dan tersedia data, untuk data primer dilakukan secara langsung seperti pengamatan dan pengukuran lasngsung dilapangan. Analisis yang digunakan dengan Intensitas Curah Hujan, Debit Limpasan, dimensi saluran pengalihan air limpasan untuk mendapatkan hasil intensitas curah hujan di area pit. untuk debit limpasan diperoleh dari air berasal dari catchment area periode ulang 5 tahunan, dengan mempertimbangkan umur tambang yang diperkirakan 10 tahun.
\end{abstract}

Kata kunci: Hidrologi, Curah Hujan, Debit impasan

\begin{abstract}
Hydrology investigations are carried out by collecting data to be analyzed for secondary meteorological data (rainfall, rainy days, air temperature, humidity, land use, etc.) from the location of the Pit 1 and Pit 2 PT.Bhakti Pertiwi Nusantara investigations. Hydrological data is the most important information for managing rainwater management systems, because the amount of rain and rainy days is very influential on the mining system. This study aims to determine the hydrological data used in the rainwater control system for utilization in the design of open mines, especially in the stability of the mine slope. This research was conducted by secondary data coagulation such as previous data and available data, for primary data conducted directly such as observations and measurements in the field directly. The analysis used is the Rainfall Intensity, Runoff Discharge, runoff channel divert dimensions to get the results of rainfall intensity in the pit area. for runoff discharge obtained from water originating from the catchment area for the 5 year return period, taking into account the estimated mine life of 10 years.
\end{abstract}

Keywords: Hydrology, Rainfall, Break Even Discharge 


\section{A. PENDAHULUAN}

PT. Bhakti Pertiwi Nusantara (BPN) sebagai Pemegang IUP (Izin Usaha Pertambangan) Produksi penambangan bijih nikel berdasarkan Surat Keputusan (SK) Bupati Halmaera Tengah Nomor : 540/KEP/161/2010 tanggal 10 Mei 2010 tentang IUP Operasi Produksi dan kembali direvisi SK tersebut dengan Nomor : 540/KEP/253/2012 tentang Persetujuan Pemberian Izin Usaha Pertambangan (IUP) Operasi. Dan berlokasi di Daerah Sepo Kecamatan Weda Utara Kabupaten Halmahera Tengah Provinsi Maluku Utara. Dengan system penambangan Tambang Terbuka maka diterapkan dengan metode open opit/cast, luas wilayah ekploitasi adalah 1.700 hektar (Gambar 1. Peta Wilayah Izin Usaha Pertambangan) dan diperkirakan memiliki cadangan bijih nikel berkadar nikel 1,35\% tidak kurang dari 100 juta wet metric ton (wmt) dengan memiliki 3 blok yaitu Pit 1, Pit 2, dan Pit 3.

PT. BPN yang berada di desa Sepo kecamatan Weda Utara yang dimana dilihat beberapa bulan terakhir terdapat intensitas curah hujan sangat tinggi, hal ini sangat berpengaruh pada system penambangan bijih nikel. Pada proses penambangan/aktifitas tidak bisa beroperasi ketika cuaca (hujan) berlangsung karena akan berakibatkan potensi kecelakaan. Sangat diperlukan perencanaan tambang dari segi geotek untuk system penanganan atau desain kestabilan lereng yang sangat efesien sehingga diperlukan juga tingkat penyelidikan Hidrologi dalam penangan Air.

Wilayah Kabupaten Halmahera Tengah untuk musim kemarau terjadi pada bulan Desember sampai Maret. Musim hujan jatuh pada bulan Mei sampai dengan Oktober yang disebabkan musim angin tenggara. Musim pancaroba terjadi pada bulan April dan Desember. Dengan kebutuhan Iklim sangat diperlukan dalam pekerjaan pertambangan dalam hal ini proses penambangan sangat diperlukan data Curah Hujan, hari hujan agar pada perencanaan tambang dapat dilakukan penyelidikan Hidrologi dan penanganan Air hujan untuk proses penambangan.

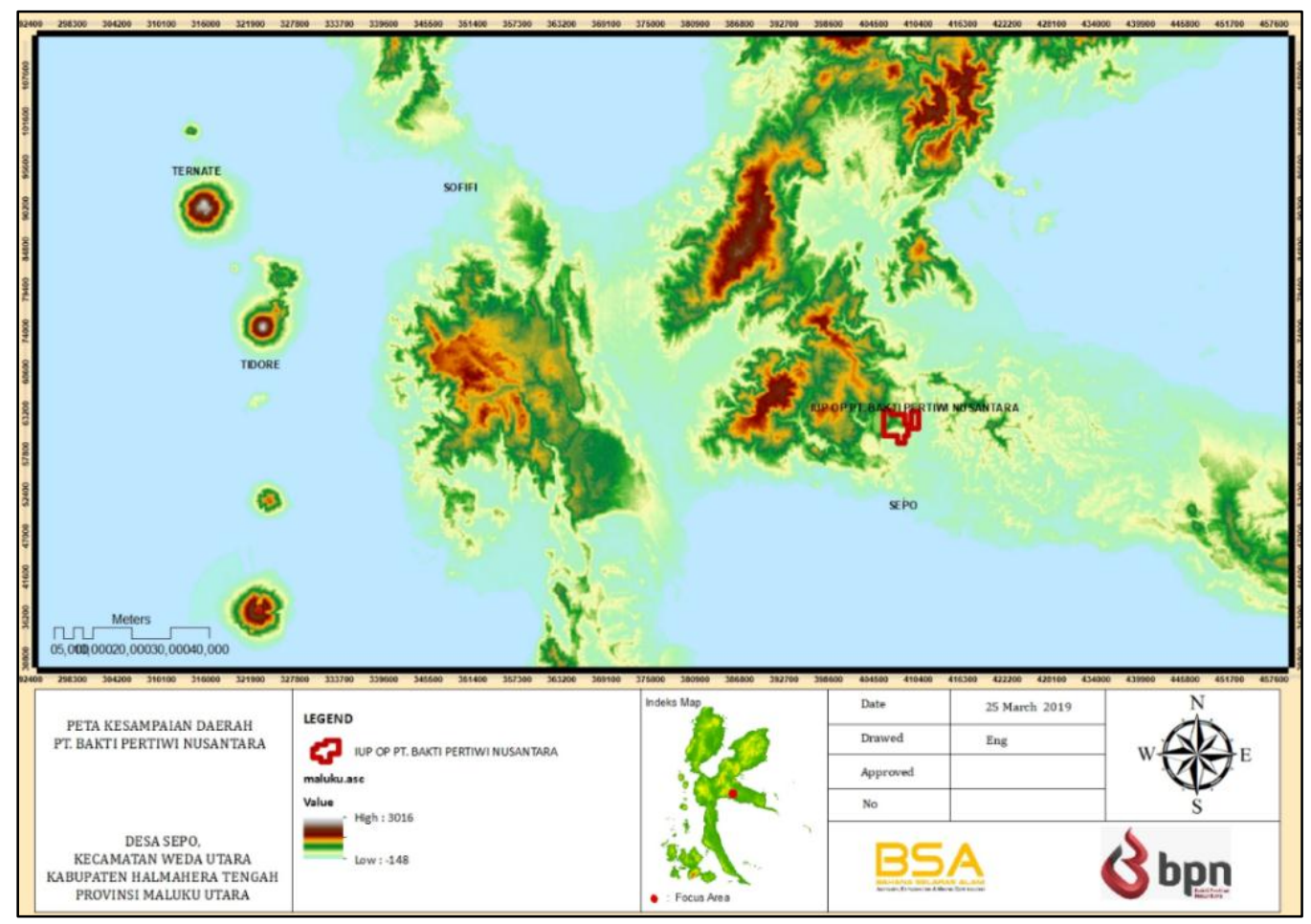

Gambar 1. Peta Wilayah Izin Usaha Pertambangan 


\section{B. METODE PENELITIAN}

Dalam penelitian ini dilakukan metode penelitian sebagai berikut :

1. Studi literatur dilakukan pada beberapa buku yang mendukung isi materi yang akan dikaji pada penelitian ini. Maka dalam penulisan ini akan ditunjang dengan latar belakang serta teori yang kuat sehingga pengolahan data, pembahasan dan kesimpulan dilakukan dengan bantuan literatur yang saling berhubungan.

2. Pengumpulan data-data yang diperlukan yaitu data primer dan data sekunder.

Data Primer merupakan data yang berdasarkan pengamatan langsung di lapangan dan Data Sekunder, diperoleh dari arsip perusahaan yang telah tersedia.

\section{ANALISA DATA}

Tahap analisis data ini meliputi perhitungan dari hasil pengolahan data, yaitu : perhitungan dari data curah hujan dan hari hujan dari pengumpulan data dari tahun 2014 - 2018 untuk penyelidikan Hidrologi, yang dimana akan mengetahui curah hujan yag tinggi dengan hari hujan.

\section{HASIL DAN PEMBAHASAN}

Lokasi daerah penyelidikan mempunyai perbandingan hari panas dan hari hujan per bulannya dalam setahun yang cukup tinggi. Curah hujan di daerah ini cukup tinggi dengan hari hujan antara 78 hari dan 64 hari. Hujan paling banyak dalam kurun 5 tahun terjadi pada bulan Juni 2015 untuk data curah hujan (Gambar 2.a) dengan curah hujan mencapai maksimum $418.5 \mathrm{~mm}$ per bulan (Gambar 2.b).

Dalam konteks perencanaan penambangan, perlu diperhitungkan intensitas curah hujan ( $\mathrm{mm} / \mathrm{jam})$, untuk menghitung perkiraan debit air hujan yang jatuh di dalam areal bukaan tambang dan daerah tangkapan di sekitarnya. Dan untuk hujan paling banyak dalam kurun 5 tahun terjadi pada bulan Mei 2016 untuk data curah hujan dengan curah hujan mencapai maksimum $339 \mathrm{~mm}$ per bulan.

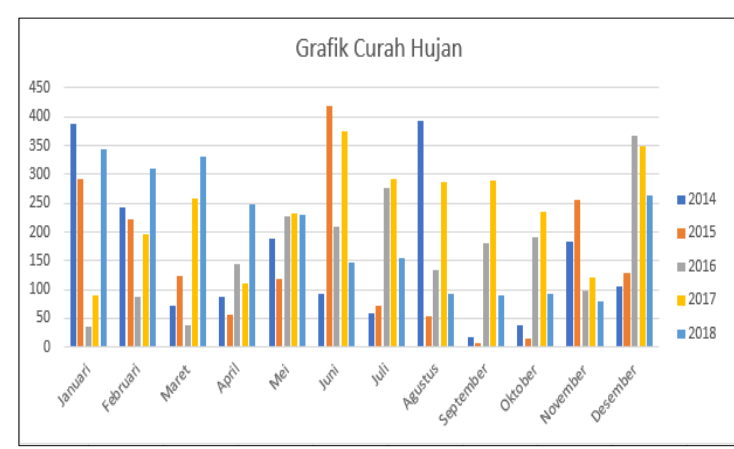

(a)

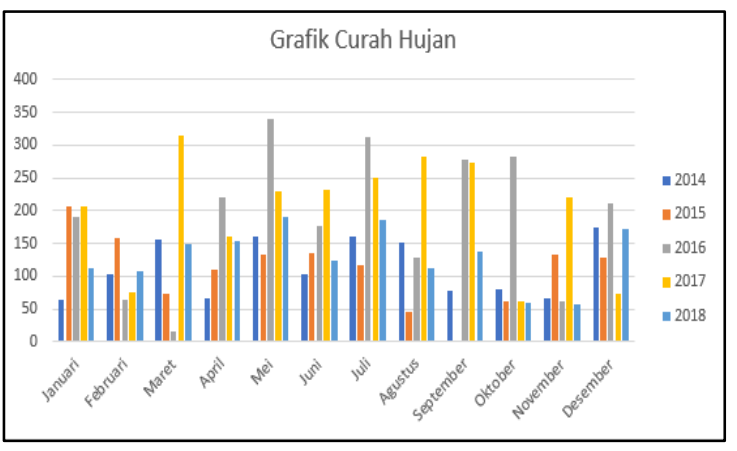

(b)

Gambar 2. (a) Data curah hujan per bulan Kecamatan Galela Kabupaten Halmahera Utara Tahun 2014-2018; (b) Curah hujan maksimum Kecamatan Galela Kabupaten Halmahera Utara Tahun 2014-2018

Berdasarkan data selama 5 tahun yang didapat, diketahui bahwa curah hujan harian maksimum dalam 24 jam $\left(\mathrm{R}_{24}\right)$ adalah $=142,389 \mathrm{~mm}$ (tabel 4.1). Dengan asumsi rata-rata waktu lamanya hujan (durasi hujan) $\mathrm{t}=1$ jam, maka besarnya intensitas hujan $\mathrm{I}$, dapat dihitung sebagai berikut.

$$
\begin{aligned}
& \mathrm{I}=\left(\mathrm{R}_{24}: 24\right) \times(24 / \mathrm{t})^{2 / 3}=(410,7199 \mathrm{~mm}: 24) \times(24 / 1 \mathrm{jam})^{2 / 3} \\
& \mathrm{I}=142,389 \mathrm{~mm} / \mathrm{jam} .
\end{aligned}
$$




\section{a. Standar Deviasi}

Untuk data curah hujan 2014-2018 Kecamatan Galela Kabupaten Halmahera Utara) mempunyai Standar Deviasi yang di dapatkan sebesar 31,085.

Tabel 1. Perhitungan Distribusi Gumbell Curah hujan 2014-2018 Kecamatan Galela Kabupaten Halmahera Utara

\begin{tabular}{ccccc}
\hline Tahun & $\begin{array}{c}\text { CH Max } \\
(\mathrm{X})\end{array}$ & $\overline{\boldsymbol{X}}$ & $\mathrm{X}-\overline{\boldsymbol{X}}$ & $(\mathrm{X}-\overline{\boldsymbol{X}})^{2}$ \\
\hline 2014 & 393 & 374.5 & 18.5 & 342.3 \\
\hline 2015 & 418.5 & 374.5 & 44 & 1936 \\
\hline 2016 & 367 & 374.5 & -7.5 & 56.3 \\
\hline 2017 & 350 & 374.5 & -24.5 & 600.3 \\
\hline 2018 & 344 & 374.5 & -30.5 & 930.3 \\
\hline Total & 1872.5 & 1872.5 & 0 & 3865 \\
\hline
\end{tabular}

\section{b. Reduksi Standar Deviasi}

Tabel 2. Perhitungan Reduksi Standar Deviasi Curah hujan 2014-2018

Kecamatan Galela Kabupaten Halmahera Utara

\begin{tabular}{cccccccc}
\hline $\mathrm{n}$ & $\mathrm{m}$ & $\mathrm{Xi}$ & $\mathrm{Yn}$ & $\overline{\boldsymbol{Y n}}$ & $\mathrm{Yn}-\overline{\boldsymbol{Y n}}$ & $(\mathrm{Yn}-\overline{\boldsymbol{Y n}})^{2}$ & $\mathrm{Sn}$ \\
\hline 5 & 2 & 393 & 0.75 & 0.56 & 0.19 & 0.04 & 0.38 \\
\hline 5 & 1 & 418.5 & 1.10 & 0.56 & 0.54 & 0.29 & 0.38 \\
\hline 5 & 3 & 367 & 0.52 & 0.56 & -0.04 & 0.00 & 0.38 \\
\hline 5 & 4 & 350 & 0.32 & 0.56 & -0.24 & 0.06 & 0.38 \\
\hline 5 & 5 & 344 & 0.11 & 0.56 & -0.45 & 0.20 & 0.38 \\
\hline
\end{tabular}

\section{c. Standar Deviasi}

Untuk data curah hujan 2014-2018 Kecamatan Galela Kabupaten Halmahera Utara Standar Deviasi yang didapatkan sebesar 76,233.

Tabel 3. Perhitungan Distribusi Gumbell Curah Hujan 2014-2018 Kecamatan Subaim Kabupaten Halmahera Timur

\begin{tabular}{ccccc}
\hline Tahun & $\begin{array}{c}\text { CH Max } \\
(\mathrm{mm})\end{array}$ & $\overline{\boldsymbol{X}}$ & $\mathrm{X}-\overline{\boldsymbol{X}}$ & $(\mathrm{X}-\overline{\boldsymbol{X}})^{2}$ \\
\hline 2014 & 174 & 245 & -71 & 5041 \\
\hline 2015 & 207 & 245 & -38 & 1444 \\
\hline 2016 & 339 & 245 & 94 & 8836 \\
\hline 2017 & 315 & 245 & 70 & 4900 \\
\hline 2018 & 190 & 245 & -55 & 3025 \\
\hline
\end{tabular}

\section{d. Reduksi Standar Deviasi}

Tabel 4. Perhitungan Reduksi Standar Deviasi Curah hujan 2014-2018 Kecamatan Subaim Kabupaten Halmahera Timur

\begin{tabular}{cccccccc}
\hline $\mathrm{n}$ & $\mathrm{m}$ & $\mathrm{Xi}$ & $\mathrm{Yn}$ & $\overline{\boldsymbol{Y n}}$ & $\mathrm{Yn}-\overline{\boldsymbol{Y n}}$ & $(\mathrm{Yn}-\overline{\boldsymbol{Y n}})^{2}$ & $\mathrm{Sn}$ \\
\hline 5 & 5 & 174 & 0.109 & 0.561 & -0.453 & 0.205 & 0.385 \\
\hline 5 & 3 & 207 & 0.521 & 0.561 & -0.040 & 0.002 & 0.385 \\
\hline 5 & 1 & 339 & 1.101 & 0.561 & 0.540 & 0.292 & 0.385 \\
\hline 5 & 2 & 315 & 0.754 & 0.561 & 0.193 & 0.037 & 0.385 \\
\hline 5 & 4 & 190 & 0.321 & 0.561 & -0.240 & 0.058 & 0.385 \\
\hline
\end{tabular}


Hasil perhitungan curah hujan rencana dengan metode distribusi Gumbel kemudian dikorelasikan dengan rumus Mononobe untuk menghitung Intensitas. Hujan rencana untuk periode ulang tertentu yang diestimasi, sebagai dalam tabel berikut.

Tabel 5. Intensitas Hujan Rencana untuk periode ulang

Kecamatan Galela Kabupaten Halmahera Utara

\begin{tabular}{cccccc}
\hline $\begin{array}{c}\text { Periode Ulang } \\
\text { Hujan (Tt) }\end{array}$ & $\begin{array}{c}\text { Resiko Hidrologi } \\
\text { (Pr) } \%\end{array}$ & Yt & k & Xt & I (mm.jam) \\
\hline 1 & 100 & 0 & -1.46 & 329.16 & 114.11 \\
\hline 2 & 75 & 0.52 & -0.11 & 371.15 & 128.67 \\
\hline 3 & 56 & 0.75 & 0.49 & 389.72 & 135.11 \\
\hline 4 & 44 & 0.903 & 0.17 & 379.81 & 131.67 \\
\hline 5 & 36 & 1.01 & 1.17 & 410.72 & 142.39 \\
\hline
\end{tabular}

Tabel 6. Intensitas Hujan Rencana untuk periode ulang Kecamatan Subaim Kabupaten Halmahera Timur

\begin{tabular}{cccccc}
\hline $\begin{array}{c}\text { Periode Ulang } \\
\text { Hujan (Tt) }\end{array}$ & $\begin{array}{c}\text { Resiko Hidrologi } \\
\text { (Pr) \% }\end{array}$ & Yt & k & Xt & I (mm.jam) \\
\hline 1 & 100 & 0 & -1.46 & 133.81 & 46.388283 \\
\hline 2 & 75 & 0.52 & -0.11 & 236.79 & 82.089739 \\
\hline 3 & 56 & 0.75 & 0.49 & 282.34 & 97.880768 \\
\hline 4 & 44 & 0.903 & 0.89 & 312.64 & 108.38523 \\
\hline 5 & 36 & 1.01 & 1.17 & 333.83 & 115.7315 \\
\hline
\end{tabular}

\section{D.1. Catchment Area}

Daerah tangkapan air hujan (catchment area) ditentukan berdasarkan studi pada peta topografi hasil olah data peta kontur situasi tambang. Untuk daerah rencana penambangan terdapat 4 (empat) catchment area yang berpengaruh terhadap rencana Pit area, yaitu :
a. Catchment area 1 (CA-1), dengan luas $49620,346 \mathrm{~m}^{2}$
b. Catchment area 2 (CA-2), dengan luas $43765,679 \mathrm{~m}^{2}$
c. Catchment area 3 (CA-3), dengan luas $32549.524 \mathrm{~m}^{2}$
d. Catchment area 4 (CA-4), dengan luas $53153.175 \mathrm{~m}^{2}$

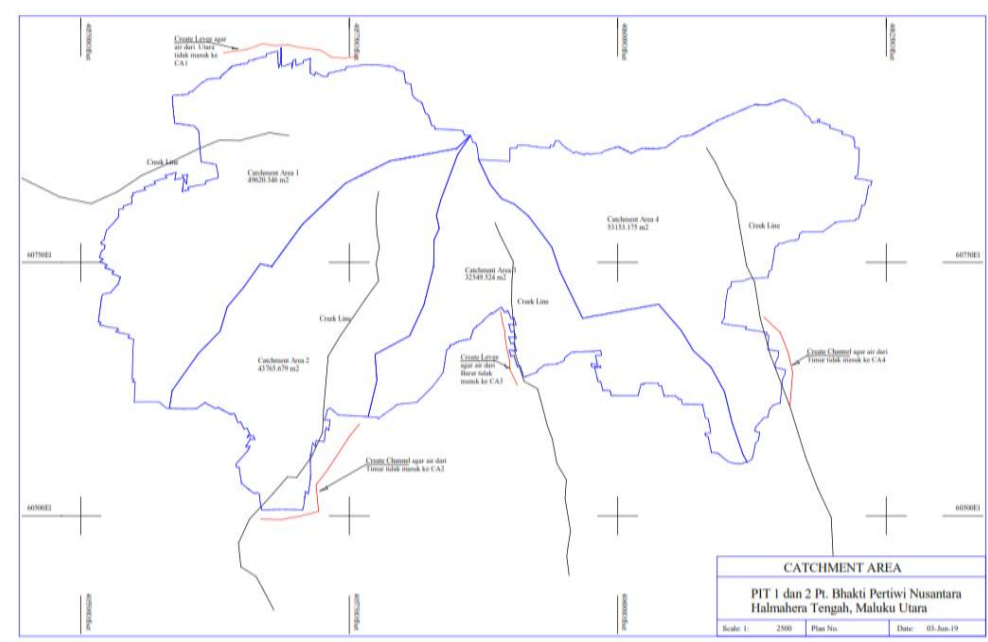

Gambar 3. Peta Catchment Area 
Untuk mengurangi air yang yang masuk ke dalam pit tambang bijih nikel maka perlu dilakukan beberapa usaha untuk mengurangi catchment area. Dengan melihat peta terlampir usaha-usaha tersebut adalah :

a. Catchment Area 1 (CA1), Perlu dibuat levee atau tanggul sedemikian rupa sehingga air dari Utara CA1 bisa dialihkan keluar dari CA1. Sehingga CA1 luasnya hanyalah luas dari pit sehingga volume airnya akan lebih kecil.

b. Catchment Area 2 (CA2), Perlu dibuat chanel atau saluran sedemikian rupa sehingga air dari sebelah Barat Selatan dari CA2 itu tidak masuk kedalam pit namun dialihkan menuju Selatan sehingga akan mengurangi CA2 tersebut. CA2 hanya menampung air hujan dari luas pit yang ada di CA2 saja.

c. Catchment Area 3 (CA3), Perlu dibuat levee atau tanggul sedemikian rupa sehingga air dari Barat CA3 bisa dialihkan keluar dari CA3. Sehingga CA3 luasnya hanyalah luas dari pit sehingga volume airnya akan lebih kecil.

d. Catchment Area 4 (CA4), Perlu dibuat chanel atau saluran sedemikian rupa sehingga air dari sebelah Timur dari CA4 itu tidak masuk kedalam pit namun dialihkan menuju Selatan sehingga akan mengurangi CA3 tersebut. CA4 hanya menampung air hujan dari luas pit yang ada di CA4 saja.

\section{D.2. Sistem Penanggulangan Air Tambang}

Dengan mengetahui sifat, perkiraan debit, dan pola aliran air permukaan (run off), koefisien permeabilitas lapisan batuan yang akan ditambang, dan perkiraan debit air tanah yang potensial masuk ke dalam area bukaan tambang, maka sasaran akhir dari studi hidrologi dan hidrogeologi ini adalah membuat rekomendasi sistem pengendalian air tambang secara keseluruhan. Sistem pengendalian air tambang terdiri dari pengendalian air tambang di luar Pit area dan di dalam Pit area.

\section{D.3. Penanggulangan Air Limpasan di Luar Pit Area}

Air limpasan adalah air permukaan (run off) yang berasal dari tangkapan air hujan pada catchment area. Air limpasan di luar Pit area (bukaan tambang) yang potensial mengalir menuju ke dalam Pit area harus ditanggulangi. Namun jika air hujan yang jatuh di luar catchment area akan menjauhi bukaan tambang, tidak menjadi masalah, dan akan mengalir dengan sendirinya secara alami menunju lembah terus ke sungai.

Perkiraan debit air yang akan mengalir ke dalam saluran pengalihan dalam kasus studi ini, hanya air dari luar Pit yang bersumber dari hujan dan air rembesan dari lapisan batuan perbukitan. Debit air tambang dari luar Pit area, yang sudah dihitung dalam bab IV, masingmasing Catchment area $1=491,04 \mathrm{~m}^{3} /$ detik, Catchment area $2=433,11 \mathrm{~m}^{3} /$ detik, Catchment area $3=322.11 \mathrm{~m}^{3} /$ detik, dan Catchment area $4=526,01 \mathrm{~m}^{3} /$ detik. Debit air limpasan yang dapat ditanggulangi dengan membuat saluran pengalihan di sepanjang pinggir luar Pit limit, dan mengalir secara gravitasi mengikuti konturnya menuju ke arah sungai.

Dari perhitungan debit saluran hasil simulasi, direkomendasikan saluran air limpasan berbentuk trapezium yang diperhitungkan cukup baik untuk mengalihkan air limpasan sepanjang waktu penambangan (Gambar 4.a. s/d. Gambar 4.d) dan Untuk catchment area 1, 2, 3, dan 4, dengan simulasi, saluran di sekeliling Pit area tambang bijih nikel dapat ditentukan dan diperhitungkan cukup untuk dapat dialiri air limpasan sejumlah yang sudah dihitung tersebut. Dimensi saluran yang direkomendasikan, adalah sebagaimana dalam Tabel 7. 
Tabel 7. Dimensi minimal Saluran Pengalihan Air di luar Pit

\begin{tabular}{clcccc}
\hline No & \multicolumn{1}{c}{ Geometri Paritan } & CA 1 & CA 2 & CA 3 & CA 4 \\
\hline 1 & Debit Air Limpasan $(\mathrm{m} / \mathrm{sec})$ & 491.04 & 433.11 & 322.11 & 526.01 \\
\hline 2 & Lebar Atas Paritan $(\mathrm{m})$ & 6.29 & 5.63 & 5.38 & 4.82 \\
\hline 3 & Lebar Dasar Paritan $(\mathrm{m})$ & 2.86 & 4.25 & 2.45 & 1.28 \\
\hline 4 & Kedalaman Paritan $(\mathrm{m})$ & 2.57 & 11.76 & 3.67 & 4.41 \\
\hline 5 & Kemiringan Dinding & $1.5: 1$ & $1.5: 1$ & $1.5: 1$ & $1.5: 1$ \\
\hline 6 & Luas Penampang Basah & 18.41 & 54.84 & 7.78 & 11.25 \\
\hline 7 & Keliling Basah & 8.83 & 117.78 & 7.54 & 7.40 \\
\hline 8 & Gradient $(\%)$ & 0.01 & 0.01 & 0.01 & 0.01 \\
\hline 9 & Koefisien Manning & 0.025 & 0.025 & 0.025 & 0.025 \\
\hline 10 & Debit Maks Paritan & 1132.14 & 1738.12 & 349.45 & 731.487 \\
\hline 11 & Kecepatan Aliran $(\mathrm{m} / \mathrm{sec})$ & 61.50 & 31.70 & 349.45 & 65.03 \\
\hline 12 & Kecepatan Aliran $(\mathrm{km} / \mathrm{jam})$ & 221.41 & 114.11 & 44.94 & 1.39 \\
\hline
\end{tabular}

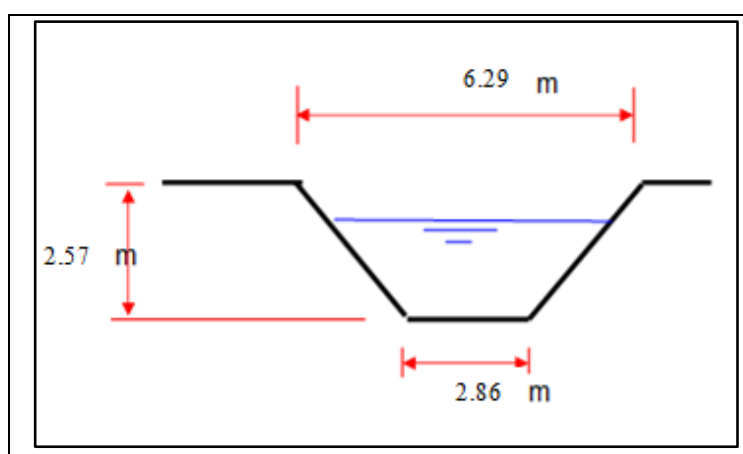

(a) Geometri Paritan untuk CA 1

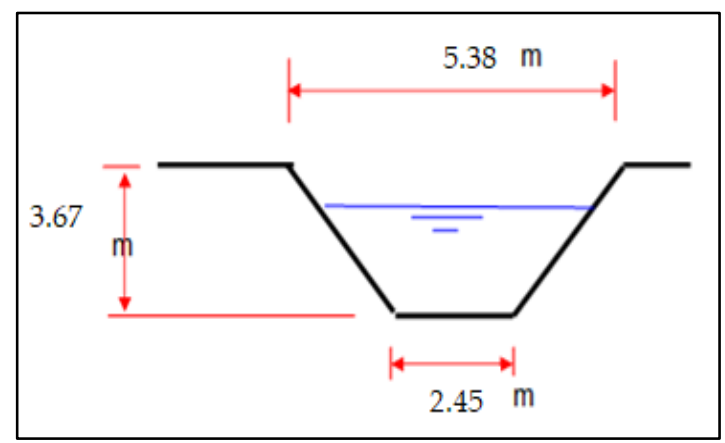

(c) Geometeri Paritan Untuk CA 3

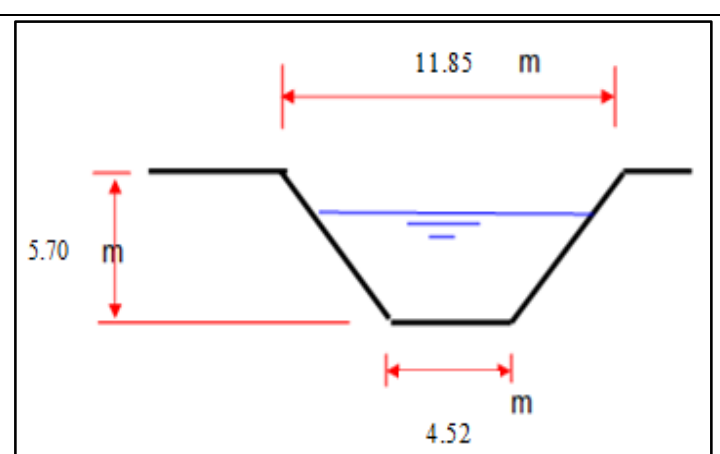

(b) Geometri Paritan untuk CA 2

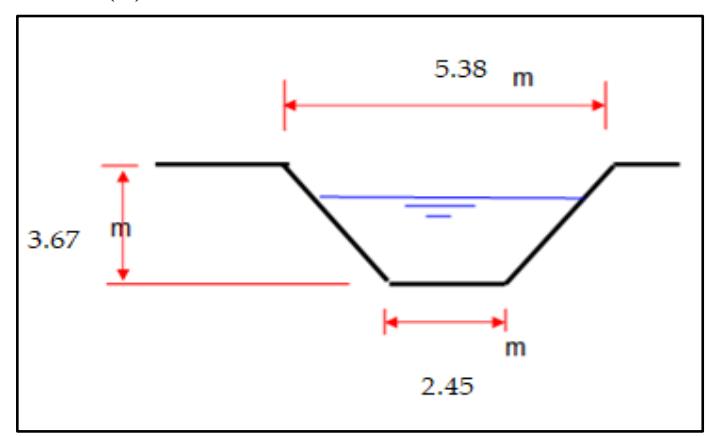

(d). Geometeri Paritan Untuk CA 4

Gambar 4. Geometri Paritan

\section{D.3.1 Penanggulangan Air Limpasan Pada Catchment Area 1}

Air limpasan dari Catchment Area 1, karena topografinya, tidak memungkinkan ditanggulangi dengan membuat saluran disisi Pit dan mengalirkannya secara gravitasi ke luar Pit area. Oleh karena itu, yang dapat dilakukan adalah dengan mengalirkannya melalui saluran dari utara ke selatan sepanjang $650 \mathrm{~m}$, dan dari selatan ke utara sepanjang $375 \mathrm{~m}$.

\section{D.3.2. Penanggulangan Air Limpasan Pada Catchment Area 2}

Penanggulangan air limpasan dari Catchment Area 2, dilakukan dengan cara membuat saluran pengalihan di sepanjang pinggir luar Pit limit, dan diupayakan dapat mengalir secara gravitasi mengikuti konturnya menuju ke arah sungai yang mengalir ke luar area tambang. 


\section{D.3.3. Penanggulangan Air Limpasan Pada Catchment Area 3}

Penanggulangan air limpasan dari Catchment Area 3 sama halnya dengan yang terdapat pada Catchment Area 2, dilakukan dengan cara membuat saluran pengalihan di sepanjang pinggir luar Pit limit, dan diupayakan dapat mengalir secara gravitasi mengikuti konturnya menuju ke arah sungai yang mengalir ke luar area tambang.

\section{D.3.4. Penanggulangan Air Limpasan Pada Catchment Area 4}

Penanggulangan air limpasan dari Catchment Area 4 sama halnya dengan yang terdapat pada Catchment Area 2 dan Catchment Area 3, dilakukan dengan cara membuat saluran pengalihan di sepanjang pinggir luar Pit limit, dan diupayakan dapat mengalir secara gravitasi mengikuti konturnya menuju ke arah sungai yang mengalir ke luar area tambang.

\section{D.4 Penanggulangan Air di dalam Pit Area}

\section{D.4.1. Sistem Penanggulangan Air Pada Jenjang}

Sistem penyaliran air pada jenjang ini, bertujuan untuk mengatur aliran air pada permukaan jenjang agar tidak terjadi genangan pada permukaan jenjang, dan dapat mengalir menuju sumuran pada lantai tambang. Pada setiap level jenjang, dibuat saluran arah vertikal yang menghubungkan antar level jenjang dengan jarak horizontal setiap $60 \mathrm{~m}$. Pada lantai tambang di level terendah dibuat sumuran (Pit sump) yang berfungsi sebagai tempat penampungan akhir semua air di dalam Pit area, sebelum dialirkan ke luar dengan sistem pemompaan. Air di dalam Pit sump biasanya dipompakan ke settling pond, yang biasanya dibuat di bagian atas dan berada di luar Pit. Air pada settling pond ini kemudian dialirkan menuju ke kolam pengontrol (monitoring pond) untuk memantau kualitas airnya, sebelum dialirkan menuju ke sungai.

\section{D.4.2. Kajian Kebutuhan Pompa Pada Areal Pit-1 dan Pit-2}

Penelitian Hidrologi dilakukan dengan cara pengumpulan dan analisis terhadap data sekunder meteorologi dan dari daerah penelitian di sekitarnya, serta penentuan luas catchment area.

Dalam hal ini, penelitian hidrologi dapat menentukan besarnya debit air limpasan yang berpotensi masuk ke area penambangan.

a. Debit Air Limpasan pada Pit-1 dan Pit-2

Karena Open pit PT. Bhakti Pertiwi Nusantara di dataran tinggi, puncak pit dan daerah luar pit morfologinya curam sehingga air hujan yang jatuh mengalir keluar pit, potensi air limpasan dari luar pit hanya sedikit dan dianggap tidak ada.

Tabel 8. Perhitungan Debit Air Limpasan di Dalam PIT

\begin{tabular}{cccccccc}
\hline PIT & $\begin{array}{c}\text { Luas } \\
\left(\mathrm{m}^{2}\right)\end{array}$ & $\begin{array}{c}\text { Hektar } \\
(\mathrm{Ha})\end{array}$ & $\begin{array}{c}\text { Intensitas } \\
\text { Curah } \\
\text { Hujan } \\
(\mathrm{mm} / \mathrm{jam})\end{array}$ & $\begin{array}{c}\text { Intensitas } \\
\text { Curah } \\
\text { Hujan } \\
(\mathrm{m} / \mathrm{jam})\end{array}$ & $\begin{array}{c}\text { Koefisien } \\
\text { Limpasan }\end{array}$ & $\begin{array}{c}\text { Debit Air } \\
\text { Limpasan } \\
\left(\mathrm{m}^{3} / \mathrm{jam}\right)\end{array}$ & $\begin{array}{c}\text { Debit Air } \\
\text { Limpasan } \\
\left(\mathrm{m}^{3} / \mathrm{detik}\right)\end{array}$ \\
\hline 1 & 109.000 & 10.9 & 0.85 & 0.00085 & 0,9 & 83,385 & 0,023163 \\
\hline 2 & 64.000 & 6.4 & 0.85 & 0.00085 & 0,9 & 48,96 & 0,0163 \\
\hline
\end{tabular}

b. Debit Air Tanah

Tabel 9. Debit air tanah total kondisi Pit aktual

\begin{tabular}{ccc}
\hline Rekapitulasi Total & $\mathrm{Q}\left(\mathrm{m}^{3} /\right.$ detik $)$ & $\mathrm{Q}\left(\mathrm{m}^{3} / \mathrm{jam}\right)$ \\
\hline PIT 1 & 0,005 & 18 \\
\hline PIT 2 & 0,004 & 14,4 \\
\hline Total & 0,009 & 32,4 \\
\hline
\end{tabular}

c. Estimasi Jumlah Pompa

Jumlah pompa yang dibutuhkan untuk mengantisipasi air hujan yang masuk kedalam Pit-1 dan Pit-2 yang harus dipersiapkan masing-masing 1 (satu) buah pompa sebagaimana terdapat pada Tabel 4.10 berikut : 
Tabel 4.10. Debit air yang masuk ke dalam Pit dan estimasi pemompaan

\begin{tabular}{cccccccc}
\hline $\begin{array}{c}\text { Kondisi } \\
\text { PIT }\end{array}$ & $\begin{array}{c}\text { Air } \\
\text { Hujan } \\
\left(\mathrm{m}^{3} / \mathrm{jam}\right)\end{array}$ & $\begin{array}{c}\text { Air } \\
\text { Tanah } \\
\left(\mathrm{m}^{3} / \mathrm{jam}\right)\end{array}$ & $\begin{array}{c}\mathrm{Q} \\
\left(\mathrm{m}^{3} / \mathrm{jam}\right)\end{array}$ & $\begin{array}{c}\mathrm{Q} \\
\left(\mathrm{m}^{3} / \mathrm{hari}\right)\end{array}$ & $\begin{array}{c}\text { Kapasitas } \\
\text { Pompa } \\
\left(\mathrm{m}^{3} / \mathrm{jam}\right)\end{array}$ & $\begin{array}{c}\text { Jam } \\
\text { Kerja } \\
\text { Pompa }\end{array}$ & $\begin{array}{c}\text { Estimasi } \\
\text { Pompa }\end{array}$ \\
\hline 1 & $\mathrm{~A}$ & $\mathrm{~B}$ & $\mathrm{~A}+\mathrm{B}$ & $(\mathrm{A}+\mathrm{B}) * 24$ & $\mathrm{C}$ & $\mathrm{D}$ & $(\mathrm{A}+\mathrm{B}) * 24 /\left(\mathrm{C}^{*}\right)$ \\
\hline 2 & 48,385 & 18 & 101,85 & 8657.25 & 1500 & $12 \mathrm{jam}$ & 1 \\
\hline
\end{tabular}

\section{E. KESIMPULAN}

1) Curah Hujan di lokasi penelitian sangat tinggi, hujan dalam kurun waktu 5 tahun pada bulan Juni 2015 dan mei 2016, dengan curah hujan mencapai maksimum 418.5mm dan $339 \mathrm{~mm}$ per bulan.

2) Pada lokasi rencana penambangan terdapat 4 (empat) Catchment area.

3) Berdasarkan perhitungan debit saluran hasil simulasi, direkomendasi saluran air berbentuk trapeszium yang diperhitungkan cukup baik agar dapat mengalihkan air limpasan sepanjang waktu penambangan.

\section{UCAPAN TERIMA KASIH}

Ucapan terima kasih dan penghargaan kepada pihak pimpinan dan staf karyawan PT. Bakti Pertiwi Nusantara Site Sepo Kecamatan Weda Utara Kabupaten Halmahera Tengah Provinsi Maluku Utara yang telah mengizinkan kami untuk melakukan penelitian, dan terima kasih juga pada instansi yang terkait. Tak lupa pula kepada teman-teman yang terlibat dalam penelitian dengan ini kami ucapkan banyak terima kasih.

\section{PUSTAKA}

Chow, V., Te., 1992, Hidrolika Saluran Terbuka (Open Channel Hydrolics) Terjemahan Erlangga, Jakarta

Gupta, S. Ram, 1989, Hidrology and Hydarulic system.Prentic Hall. New Jersey. Lampung.

Gautama, R., S., 1995, Diktat Sistem Penyaliran Tambang, Jurusan Teknik Pertambangan, ITB, Bandung

Kite, G. W., 1977, Frequency and risk analyses in hydrology, Water Resources Publications, Fort Collins, Colorado

Mori, K., 1975, Manual of Hidrology, Terjemahan, Pradnya Paramita, Jakarta

Sosrodarsono, S., dan Takeda., 1980, Hidrologi untuk Pengairan. Pradnya Paramita, Jakarta 
PROSIDING TPT XXVIII PERHAPI 2019 